IJPBL

Interdisciplinary Journal of Problem-Based Learning

Volume 10 | Issue 1

Article 3

Published online: 9-11-2015

\title{
The Effect of Senior Medical Student Tutors Compared to Faculty Tutors on Examination Scores of First- and Second-Year Medical Students in Two Problem-Based Learning Courses
}

\author{
Damon H. Sakai \\ John A. Burns School of Medicine at the University of Hawaii at Manoa, damon@hawaii.edu \\ Marcel D'Eon \\ University of Saskatchewan, marcel.deon@usask.ca \\ Krista Trinder \\ University of Saskatchewan, krista.trinder@usask.ca \\ Richard T. Kasuya \\ John A. Burns School of Medicine at the University of Hawaii, kasuya@hawaii.edu
}

IJPBL is Published in Open Access Format through the Generous Support of the Teaching Academy at Purdue University, the School of Education at Indiana University, and the Jeannine Rainbolt College of Education at the University of Oklahoma.

\section{Recommended Citation}

Sakai, D. H. , D'Eon, M. , Trinder, K. , \& Kasuya, R. T. (2016). The Effect of Senior Medical Student Tutors Compared to Faculty Tutors on Examination Scores of First- and Second-Year Medical Students in Two Problem-Based Learning Courses. Interdisciplinary Journal of Problem-Based Learning, 10(1).

Available at: https://doi.org/10.7771/1541-5015.1533

This document has been made available through Purdue e-Pubs, a service of the Purdue University Libraries. Please contact epubs@purdue.edu for additional information.

This is an Open Access journal. This means that it uses a funding model that does not charge readers or their institutions for access. Readers may freely read, download, copy, distribute, print, search, or link to the full texts of articles. This journal is covered under the CC BY-NC-ND license. 


\title{
THE INTERDISCIPLINARY JOURNAL OF PROBLEM-BASED LEARNING
}

\section{ARTICLE \\ The Effect of Senior Medical Student Tutors Compared to Faculty Tutors on Examination Scores of First- and Second-Year Medical Students in Two Problem-Based Learning Courses}

\author{
Damon H. Sakai (John A. Burns School of Medicine at the University of Hawaii at Manoa), Marcel D'Eon \\ (University of Saskatchewan), Krista Trinder (University of Saskatchewan), and Richard T. Kasuya
}

(John A. Burns School of Medicine at the University of Hawaii at Manoa)

\begin{abstract}
At the University of Hawaii John A. Burns School of Medicine, senior medical student volunteers are used as tutors for some problem-based learning groups in both the first and second years. Previous studies on the advantages and disadvantages of student tutors compared to faculty tutors have been equivocal. This study expected to answer the following question: Are there differences in examination scores for learners in their first or second year tutored by fourth-year medical students compared to those tutored by faculty members on two different types of examinations? Students were assessed using more clinically relevant, modified essay question examinations and multiple-choice question examinations. Student grades for eight consecutive years were sorted for year and type of examination into those tutored by a faculty member and those tutored primarily by a senior medical student. The only difference favored faculty tutors on second-year examinations that contained more clinically relevant questions. This phenomenon may be explained by the clinical expertise of faculty tutors making a difference in the second year but not the first year.
\end{abstract}

Keywords: problem-based learning, curriculum and instruction, medical education

Some medical schools use senior medical students as problem-based learning (PBL) tutors to provide learners with the unique benefits that student tutors offer (Kassab, Abu-Hijleh, Al-Shboul, \& Hamdy, 2005; Moust \& Schmidt, 1995) and to facilitate the personal and professional benefits that generally accrue to the senior student tutors (Ross \& Cameron, 2007; Ten Cate \& Durning, 2007a, 2007b). While some studies have shown advantages to using students or faculty as tutors, other studies have shown no differences between the two (Schmidt \& Moust, 2000). It is important to the medical schools that utilize senior students as PBL tutors to determine whether or not the learning outcomes are the same for the learners in groups tutored by senior students compared to groups tutored by faculty.

\section{Content Expertise and Group Processing Skills}

The literature has generally described student tutors as nonexpert, near-peer mentors with strong group process skills (Albanese \& Mitchell, 1993; Bulte, Betts, Garner, \& Durning, 2007; Moust \& Schmidt, 1995; Sobrol, 1994; Ten Cate \& Durning, 2007a, 2007b). The debate on the value of content expertise compared to strong group process skills has not yet been settled, as neither content expertise nor the PBL process has been properly defined (Albanese \& Mitchell, 1993; Schmidt \& Moust, 2000). Researchers and scholars are not sure how to define content expertise within the context of PBL groups. Are content experts physicians in general, physicians with specialized knowledge in the area being learned, or basic scientists? It 
is not surprising that studies that compare content experts with nonexperts are inherently weak. Similarly, and compounding this issue, PBL group process skills are not well understood or explained, especially with respect to their importance in varying degrees for different situations (Barrows, 1986; Schmidt \& Moust, 2000). There are also many variants of PBL depending on the location and sometimes even the tutor within a single medical school (Barrows, 1986). While students clearly have less experience with patients and are still junior learners compared to practicing physicians, it cannot be said that physicians do not have strong group process skills and are categorically less skilled PBL facilitators than students. Describing student tutors as strong facilitators with effective process skills and physicians as content experts with lower levels of group process skills is neither helpful nor accurate. We argue that this lack of definitional clarity contributes to the mixed and sometimes contradictory evidence: some studies favor process skills over content expertise and others show an advantage for content expertise (Davis, Nairn, Paine, Anderson, \& Oh, 1992; Eagle, Harasym, \& Mandin, 1992; Zeitz \& Paul, 1993). Nevertheless, we have used this working definition of group process skills: facilitating the PBL process by managing the flow of new information from the case, ensuring thorough and relatively equal independent research, assessing student performance, and helping the group to address any conflicts that may arise. We contrast group process skills with content expertise: knowledge and understanding of the biomedical, clinical, and human dimensions of the situation represented in the case. Though open to critique, these are the rough conceptualizations that we have in mind and that infuse this article.

Das, Mpofu, Hasan, and Stewart (2002) added refreshing complexity to the discussion on PBL processes, noting that successful tutors initially give more help and support to students but expect them to be more self-directed later on (Das et al., 2002). A developmental framework was also proposed by Albanese (2010), who noted that strong process skills were only needed initially, when students were unfamiliar with PBL. These empirical findings support a theory of tutor performance that includes cognitive congruence-namely the ability of the tutor to understand the learning needs of the student and help the learners to connect the new knowledge to their existing knowledge structures (Schmidt \& Moust, 2000). Students grow throughout their medical school careers, so the approach of PBL tutors should adjust to meet their needs as they develop throughout their medical school careers. Similarly, there may be a role for student and faculty tutors at different stages of medical school where their unique strengths may be of greater use to the learners. Adapting and modifying teaching based on the needs of the learners is consistent with theories of developmental psychology (Piaget, 1971; Ten Cate \& Durning, 2007a; Vygotsky, 1978).

\section{Learning Outcomes}

While some studies have shown better learning outcomes with faculty tutors (Moust, de Volder, \& Nuy, 1989; de Volder, de Grave, \& Gijselaers, 1985), others have not (Kassab et al., 2005; Moust \& Schmidt, 1995; Schmidt \& Moust, 2000; Sobrol, 1994). Ten Cate, van de Vorst, \& van den Broek (2012) recently indicated a slight advantage with near-peer tutors (Cohen's $d=0.17$ ) (Ten Cate et al., 2012). It is important to note that Moust et al. (1989), working in a law school, included different types of examinations as a factor, and found that law students in faculty-tutored groups had higher performance on essay questions relevant to practice. This is the only study within a PBL curriculum that examined the effect of faculty tutors on a particular type of learning. Though the Moust et al. (1989) study was not conducted in a medical school with medical students as the others were, we do think that their findings likely apply to PBL in medical schools as well. This assertion has not been tested. Both law and medical school PBL tutors with content expertise tend to use their background knowledge to direct discussions and to probe for deeper understanding, while those with less content expertise tend to facilitate the group process better, pressing the students to think more deeply and to find their own answers to their questions (Dolmans et al., 2002; Kassab et al., 2005; Moust \& Schmidt, 1995). Comparing student and faculty tutors is confounded not only by the unresolved question of group process skills compared to content expertise, but also by the influence of the unique contributions that all types of tutors with strong cognitive congruence may bring to the learning environment.

\section{Senior Student and Physician Tutors}

Senior student tutors may be better able to reassure and guide younger students who are anxious about learning in a selfdirected curriculum and who are uncertain about their place in the organization. Providing support at this stage of medical school is a key behavior of successful tutors (Das et al., 2002) and near-peer mentors (Ten Cate \& Durning, 2007a, 2007b), though the strength of this contribution and the mechanisms by which this nurturing behavior helps learners has not been fully explained. A potential weakness of senior students (i.e., they are not experts) ironically may be a source of strength if one considers that senior student tutors are less intimidating, more approachable, and may be better able to explain concepts in a manner that is understandable to junior students (Moust \& Schmidt, 1995; Ten Cate \& Durning, 2007a; Topping, 1996). We have also observed over years of experience that student tutors are more likely to remember 
the basic science concepts and principles that many experienced clinicians may have long forgotten that may be very helpful for preclerkship medical students. Student tutors are a unique combination of both content expertise relative to more junior learners and group process skills, and thus may have the ability to meet the psychosocial and practical needs of less-experienced medical students.

Physician tutors in particular bring clinical experience and expertise to the tutorial group. They see more complexities and nuances in the patient's situations, and are in a better position to pass on to their students the key clinical insights that senior medical students do not yet have. This is the advantage of experts that is highlighted by Moust et al. (1989), who have explored law students' achievements, and by many others (Das et al., 2002; Moust \& Schmidt, 1995; Ten Cate et al., 2012). Explanations for finding no differences in achievement, in light of this expert advantage, have rested on the assumption that the better process skills and a nearpeer tutoring advantage compensate for the lack of content expertise of the student tutors (Moust \& Schmidt, 1995). As was stated earlier, while it is clear that students have less content expertise than their physician colleagues, we cannot say for sure that physicians are categorically less skilled at the PBL process.

\section{PBL at JABSOM}

The John A. Burns School of Medicine (JABSOM) uses PBL as its primary curriculum delivery method and has been utilizing senior (fourth-year) medical students as small-group tutors for first- and second-year medical student PBL groups for over 20 years. Though the vast majority of faculty tutors are physicians, JABSOM also employs senior student tutors supervised by a faculty member, who may be present in the tutorial room with the student tutor.

At JABSOM, the PBL process is generally conducted in the classic manner (Barrows, 1986; Barrows \& Wee Keng Neo, 2007; Bereiter \& Scardamalia, 2000; Walsh, 2005) with real clinical, patient-centered cases presented to students using progressive disclosure, either on paper or, more recently, on tablet computers. Consistent with this classic model, tutorial groups are confronted with a patient situation, which by design the students are not fully equipped to manage. Under the guidance of their tutors, learners work together to identify the main problem or problems, pool their existing knowledge and identify what they don't know and need to know, generate some working hypotheses and possible explanations, and agree on their shared learning priorities. Between sessions, students conduct in-depth independent study and research, and prepare themselves to teach each other about what they are learning. At the following group session, students bring their new knowledge to bear on the patient problem, and finally reflect on their learning and how they worked together as a group. While the tutor actively facilitates the process and provides some gentle guidance, the students assume ownership of much of the process and do the vast majority of the work.

There are also some unique aspects of the PBL process at JABSOM that are particularly relevant to this study. At JABSOM, each PBL group consists of five or six first- or secondyear students and a tutor. JABSOM favors and encourages active tutoring. Besides facilitating the process and keeping the group on track, the tutor (physician, basic scientist, fourth-year medical student, or in a few cases, a tutor team of two) has been trained to probe for understanding and reasoning, and encourage the synthesis and application of new knowledge to patient situations. Tutors are encouraged to share clinical or personal experiences that bring the case to life or make an issue more meaningful without imposing or diminishing the group process or student initiative. Tutors, both senior students and faculty, may even engage the learner students in role-plays that facilitate a deeper understanding of situations that arise in patient care. They are active facilitators, and physician tutors in particular are known to interject relevant clinical content derived from personal experiences, which are affectionately known as clinical "pearls."

\section{Preparation of PBL Tutors}

Prior to leading a tutorial group, all potential faculty tutors (both physicians and basic scientists) attend a PBL training workshop that consists of two four-hour sessions covering the educational rationale for PBL, the PBL process, and the role of the tutor. This training provides active, realistic practice where, under expert guidance, faculty trainee tutors work with volunteer student groups. PBL tutor trainees receive feedback on their performance and their potential to become good tutors from the faculty workshop leaders and the student volunteers. During training, tutors are encouraged to contribute clinical pearls from their own personal experiences during PBL tutorial sessions. At times novice tutors are paired with experienced tutors for supportive coaching. The training workshops are highly rated by faculty and considered to be quite effective.

Fourth-year medical students may become PBL tutors by enrolling in a credited PBL tutoring elective. Students are required to complete an application process, and only those with records of strong academic and professional performance are accepted. In contrast to faculty tutors, student tutors only attend one two-hour orientation session that emphasizes their roles and responsibilities as tutors. When tutoring a group, senior student tutors are paired with a 
faculty member, either a physician or a basic scientist, who has been carefully selected for his or her tutor skills, and that faculty tutor then serves as a mentor/supervisor for the student. When faculty members are confident that student tutors are working effectively, they have the option of attending the PBL sessions in person less frequently or for shorter periods of time. Some faculty tutors may choose to continue to attend all PBL sessions and contribute to the group discussion to varying degrees. In all cases, the student tutors generally have a great deal of autonomy and responsibility and interact with the student learners more than the faculty members who supervise them. Student tutors are usually rated very highly by their faculty supervisors and by the learners in their tutorial groups.

\section{The PBL Curriculum}

The preclerkship curriculum is divided into courses that run from 8-14 weeks each. The course entitled MDED 554: Gastrointestinal and Endocrine Systems falls at the end of the first year of the curriculum. The course covers many basic science disciplines related to the gastrointestinal system such as anatomy, histology, embryology, and physiology as well as associated diseases such as gastroesophageal reflux disease, peptic ulcer disease, ulcerative colitis, pancreatitis, hepatitis, and infectious diarrhea. More commonly known as "MD4," this course also includes the same basic science disciplines related to the endocrine system and associated diseases such as hyper-/hypothyroidism, congenital adrenal hyperplasia, and diabetes mellitus. MDED 557: The Life Cycle is offered in the second year and is more commonly referred to as "MD7." This course covers basic science topics from reproduction and obstetrics, paediatrics, and geriatrics, as well as such clinical considerations as normal physiology changes in pregnancy and geriatrics. It also covers conditions and concepts such as respiratory distress syndrome, preeclampsia, infertility, prostate cancer, delirium, maternal screening, childhood immunizations, inborn errors of metabolism, pain management, and end-of-life issues. Over the years, each of these two courses has remained essentially the same, with some minor revisions in the content and the corresponding examination questions.

\section{Student Evaluation}

Students are assessed at the end of each course with two different but related types of examinations: modified essay question (MEQ) and multiple-choice question (MCQ) examinations. The MEQ is based on the biological and clinical content found in the PBL cases, including aspects of clinical reasoning, diagnosis, and management. The MCQ is based on both basic and clinical sciences content. The MCQ examinations are machine-scored, composed entirely of multiple-choice questions, with about 80 to 100 items in each examination. The MEQ questions are scored by hand using a thorough marking guide with about 40 to 60 items in each examination. The scores are converted to percentages and then included in the student transcripts.

An independent evaluation of questions from a MEQ and a MCQ examination in the MD4 course for 2008 and the MD7 course for 2007 confirmed that the questions in the MEQ examinations addressed more clinically relevant content. Working with researchers from the University of Saskatchewan, senior medical students rated each question from the examinations for their relevance to general clinical practice. For the MD4 course, average scores of clinical relevance for the MEQ and MCQ examination questions were $0.79(S D=.09)$ and $0.64(S D=.07)$, respectively. This difference was statistically significant $(t(7)=6.51, \mathrm{p}<.001)$, with a large effect size ( $d=1.82)$ type (where .2 is considered small, .5 medium, and .8 large). For the MD7 course, average scores of clinical relevance for the MEQ and MCQ examination questions were $0.85(S D=.08)$ and $0.76(S D=.08)$ respectively. Although this difference was not statistically significant $(t(10)=-1.92, p=.083)$, likely due to small sample size, it had a large effect size $(d=-1.12)$. We also noted that both the MCQ and the MEQ examinations in the second year were rated higher for clinical relevance than those in the first year. For the MCQ examination, there was a statistically significant difference $(t(12)=-2.89, \mathrm{p}=.014)$ with a large effect size $(d=-1.53)$. The difference between the MEQ examination for MD4 and MD7 were not statistically significant, with only a moderate effect size $(t(12)=-1.34, \mathrm{p}=.204, d=-.74)$.

\section{Research Question}

Given the common use of student tutors at JABSOM and at other PBL schools, we wanted to know whether there might be an advantage to having a faculty tutor compared to having a senior student tutor in the first and second years of medical school on measures of student achievement. For two main reasons, we chose not to look at inputs (such as the different training that tutors receive and the costs associated with each type of tutor engagement). First, previous studies on this question looked only at outcome measures, and though some suggested that there were input benefits to student tutors (human resource costs), none of those studies quantified the advantages. It seemed to us that the primary question that remained unsettled was whether or not there was an advantage to having a student tutor. Second, we chose not to attempt to define or analyze the input costs since these would likely be quite different in 
different contexts, whereas we believed that any differences in outcomes might be more generalizable and might, depending on the differences, then provoke an exploration of those input costs. Since we had two types of examinations, MCQ and MEQ, each emphasizing slightly different learning outcomes, we were in a position to compare two types of achievement, similar to Moust et al. (1989): knowledge acquisition and clinical reasoning. This focused question was more interesting to us and we believed more valuable to the medical education community. Where our study differs from others and where it can make an important contribution to the literature is that we also compared learner achievement in two different years. To our knowledge there have been no studies that compared student and faculty tutors on different types of learner achievement in different years.

We therefore decided to focus on the following question:

Are there differences in scores on two types of examinations (one with more clinically relevant questions than the other) for PBL learners tutored by fourth-year medical students compared to PBL learners tutored by faculty in both the first and second year of preclerkship training?

This question is important both theoretically and practically, even though we fully expected to find that the achievement of student learners in groups tutored by senior students showed no difference compared to those student learners tutored by a faculty member. A clear answer will shed additional light on our understanding of the PBL experience and make us more curious about how various components of the PBL process contribute to student achievement. Practically, the findings from this study and others, along with additional considerations such as inputs (tutor availability and costs), may result in a reaffirmation or a reassessment of our policies regarding the engagement of student tutors.

\section{Methods}

Student grades on both MEQ and MCQ in two different courses, MD4 in first year and MD7 in second, were obtained for eight consecutive years (2003-2010, but not 2007 for MD7 as there were no student led groups that year). The grades were sorted into two groups: grades of those students tutored by a faculty member and those tutored by a senior medical student under supervision. For the first-year course, 203 students were tutored by a fourth-year student and 346 were tutored by faculty. For the second-year course, 108 students were tutored by a fourth-year student and 317 were tutored by a faculty member. We also must note that in the first-year course we studied, there were 80 facultytutored groups, which included 15 students with an MD and a $\mathrm{PhD}$ tutor team, 42 with MDs alone, 20 with basic science $\mathrm{PhDs}$ alone, and 3 with tutors working alone who had both a $\mathrm{PhD}$ and an MD. For the second-year course we studied, there were 63 faculty-tutored groups comprised of 9 students with an $\mathrm{MD}$ and a $\mathrm{PhD}$ tutor team, 51 with MDs alone, 2 with a Master's of Technology, and only one with a tutor who had both a PhD and an MD (see Table 1).

Assignment of students to groups was done purposefully-not randomly-by course planners who took into consideration educational factors such as prior academic preparation and achievement. They also tried to balance gender and state of residency. Students who seemed to be struggling academically were often placed in groups led by faculty who were known to be experienced and dedicated teachers. This may have created a situation where students in facultytutored groups had slightly lower levels of previous achievement than students in student-tutored groups. Since such placements were uncommon, and represented a tiny fraction of the class, this factor was dismissed as inconsequential and no allowances were made to mitigate or account for this phenomenon.

Table 1. Number of students by student and faculty-led groups.

\begin{tabular}{|c|c|c|}
\hline \multirow[b]{2}{*}{ Tutors } & \multicolumn{2}{|c|}{ Year of Program } \\
\hline & $\begin{array}{c}1 \text { st year } \\
(2003-2010)\end{array}$ & $\begin{array}{c}\text { 2nd year } \\
(2003-2006 ; 2008-2010)\end{array}$ \\
\hline Senior Student & 203 student learners & 108 student learners \\
\hline Faculty Members & $\begin{array}{ll} & 346 \text { student learners in } 80 \text { groups: } \\
\text { - } & 42 \mathrm{MDs} \text { alone } \\
\text { - } & 15 \mathrm{MD} / \mathrm{PhD} \text { tutor teams } \\
\text { - } & 20 \mathrm{PhDs} \text { alone } \\
\text { - } & 3 \text { tutors with both } \mathrm{MD} \& \mathrm{PhD}\end{array}$ & $\begin{array}{l}\text { 317 student learners in } 63 \text { groups: } \\
\text { - } \quad 51 \mathrm{MDs} \text { alone } \\
\text { - } \quad 9 \mathrm{MD} / \mathrm{PhD} \text { tutor teams } \\
\text { - } \quad 2 \text { other } \\
\text { - } \quad 1 \text { tutor with both } \mathrm{MD} \& \mathrm{PhD}\end{array}$ \\
\hline
\end{tabular}


Faculty tutors were also placed in groups to provide educational benefits to students. Stronger and more experienced faculty members with a $\mathrm{PhD}$ alone were often given their own groups while others were paired with an MD. Similarly, novice tutors with MDs would sometimes be paired with more experienced tutors who had PhDs. Also, the benefit of having some content knowledge in the basic science was thought to be important in the first year; hence, more $\mathrm{PhDs}$ were used as tutors in the first year. In the second year, where possible, only tutors with MDs were used, and for the seven years covered by this study, over $96 \%$ of the faculty-led groups had an MD tutor.

Given that there were three main groups of tutors-students, MDs, and PhDs-for the MD4 data for first-year students, we conducted an ANOVA and were prepared to do a post hoc analysis if we found a statistically significant difference among the three groups. For the MD7 data for secondyear students, independent sample $t$-tests were conducted to determine if there was an overall difference between the performance on the MEQ (the more clinically oriented case material) and the MCQ (the more basic and clinical science material sometimes covered as well in large group lectures) for students tutored by faculty compared to those tutored by senior students under supervision. Though the sizes of the two groups were quite different (108 and 317, respectively) we were not concerned that the assumptions needed to conduct a $t$-test were violated to the extent that our results would not be valid. Effect sizes (Cohen's $d$ ) were calculated to determine the practical significance of the differences between tutors.

This study was deemed exempt from federal regulations pertaining to the protection of human research participants by the Office of Research Compliance, Human Studies Program, of the University of Hawaii.

\section{Results}

\section{MEQ Performance}

Comparisons of scores on the MEQ examinations were conducted separately for first- and second-year students. No statistically significant difference among the three groups of tutors was found for first-year MEQ performance $(F(2,611)$ $=1.70, p=.184$ ). A statistically significant difference with a small effect size was found for second-year students, where those tutored by faculty performed on average $1.7 \%$ points better on the MEQ than those who were tutored primarily by senior medical students under supervision $(t(423)=2.90$, $p=.004, d=-.32)$. Means and standard deviations are reported in Table 2.

\section{MCQ Performance}

Comparisons of scores on the MCQ examinations were conducted separately for first- and second-year students. No statistically significant differences in MCQ performance between students in groups tutored by faculty or senior students were found for either year. An ANOVA was conducted for first-year students (MD4), yielding no statistically significant difference among the three groups of tutors $(F(2,548)=$ $2.90, p=.056)$. Post hoc analysis of effect size showed a small disadvantage for students in groups that were tutored by faculty with a $\operatorname{PhD}(d=.27$; an absolute difference of $2.53 \%)$, which as mentioned earlier was not statistically significant. Though there was a very small difference in second-year scores (students in faculty tutored groups scoring on average $0.87 \%$ points higher), it too was not statistically significant ( $p=.288, d=-.11$ ), so the difference may be due to chance or random factors in the study. Means and standard deviations for the MCQ are reported in Table 3.

Table 2. Means and standard deviations for first and second year MEQ grades by tutor group.

\begin{tabular}{|c|c|c|}
\hline \multirow{2}{*}{ MEQ Tests } & Year 1 (2003-2010) & Year 2 (2003-2006; 2008-2010) \\
\hline & Mean (Standard Deviation) & Mean (Standard Deviation) \\
\hline Student Tutored & $83.41(6.61)$ & $82.44(5.42)$ \\
\hline Faculty (MD) Tutored & $83.94(5.90)$ & $84.14(5.19)$ \\
\hline Faculty (PhD only) Tutored & $82.61(6.80)$ & NA \\
\hline
\end{tabular}


Table 3. Means and standard deviations for first and second year MCQ grades by tutor group.

\begin{tabular}{lcc}
\hline \multirow{2}{*}{ MCQ tests } & Year 1 (2003-2010) & Year 2 (2003-2006; 2008-2010) \\
\cline { 2 - 3 } & Mean (Standard Deviation) & Mean (Standard Deviation) \\
\hline Student Tutored & $74.27(8.15)$ & $75.80(7.52)$ \\
Faculty (MD) Tutored & $74.69(8.56)$ & $76.67(7.32)$ \\
Faculty (PhD) Tutored & $72.16(9.83)$ & $\mathrm{NA}$ \\
\hline
\end{tabular}

\section{Discussion}

The simple answer to our research question is, "Yes, there are differences in examination scores for learners tutored primarily by fourth-year medical students under supervision compared to scores for those tutored by faculty." In this study, we found a small difference in second-year student performance on the MEQ (reflecting more clinically relevant PBL case content and knowledge), favoring the faculty-tutored groups. This finding is consistent with Moust et al's (1989) study, which found that law students tutored by experts performed better on essay tests that were more practice oriented. There were no statistically significant differences on either type of examination for first-year students regardless of the type of tutor (student, MD, or $\mathrm{PhD}$ ).

There are likely many factors that contribute to these differences. By design, the faculty at JABSOM report that they have created a strong clinical focus in PBL cases in the second year. This is supported by the relevance data of the examinations that revealed much more clinically relevant questions in MD7 compared to MD4. Since the vast majority of faculty tutors have an MD or were paired with a tutor who had an MD (97\%), they may be better able to share key principles and clinical pearls in comparison to less clinically experienced student tutors. Faculty tutors, in particular clinical faculty, may also be better able to explain some of the intricacies of clinical decision-making, such as why one diagnostic test or medication should be used versus another. These faculty members can draw from their substantial clinical experiences to share real-life stories that make PBL topics more meaningful, exciting, and important to learn. Furthermore, second-year medical students have a stronger knowledge base on which to build than they had in the first year. Clinical pearls provided by physician tutors are more likely to be integrated into what they have already learned. To lean on the theory found in Schmidt and Moust (2000), physician tutors may be better able to develop cognitive congruence with second-year students than they are with first-year students who are relative novices. Second-year students may also require less support and encouragement (often provided by senior medical student tutors in the first year), having already mastered self-directed learning skills and adjusted to life as a medical student. With these advantages, one may wonder why the examination scores of students tutored by faculty are not higher. Again, many other factors contribute to the PBL experience: the quality of the problem or case and the prior knowledge of the students (Schmidt \& Moust, 2000), the structure and process of PBL that embeds effective pedagogical approaches (McKee, D'Eon, \& Trinder, 2005) - that is, cooperative and experiential learning - into the exploration of real-life cases, as well as the indomitable resourcefulness and effort of the medical students to learn from multiple sources.

Similarly, there are possible explanations as to why we see no differences in first-year student performance. The cases and subsequent examination questions are not designed to be as clinically complex as they are in the second year, therefore muting the alleged advantages provided by the clinical faculty tutors. Perhaps the fourth-year student tutors and the $\mathrm{PhD}$ faculty, with support from their faculty supervisors or colleagues, may have enough relevant clinical experience to guide firstyear students through these simpler clinical situations and to share meaningful stories with the student learners. Our proposed explanation needs to be investigated further.

We were surprised to find that there was not more of a pronounced difference between the MEQ and the MCQ: $d=-1.12$ for MD7 (0.85 compared to 0.76) and for MD4 $d=1.82$ (0.79 compared to 0.64$)$. If, as we suggest, a strong mechanism of action is the clinical expertise of the tutors that supports the learning related to the more clinically relevant questions, then if we were to compare achievement on those examination questions that are the most and the least clinically relevant regardless of the examination in which they were found, then the difference between faculty and student tutors might be more pronounced. It is possible that this lack of separation between the two examinations (MEQ and MCQ) may also have contributed to the small differences between student and faculty tutors. This is a clear direction for future research. 
In addition, first-year students are still trying to figure out medical school and adjust to PBL, which accentuates the advantages of having senior medical student tutors who, more often than faculty tutors, provide extra reviews during unscheduled time, are always on time and usually better organized, and have practical tips for adjusting to medical school, as informally reported by JABSOM students and corroborated by Moust and Schmidt (1995) and Das et al. (2002). This explanation, like the others, is only a working hypothesis and needs to be studied further.

This study adds to our growing understanding of the impact of a tutor on learning. Though most studies generated findings that indicated how student tutors compared to physician tutors overall, our findings are more nuanced and have highlighted two other potential factors: the level of the student and the nature of the examination (Moust et al., 1989). Our findings align well with the concept of cognitive congruence found in Schmidt and Moust (2000) and may contribute to the development of a better theory of the PBL tutor. We cannot say that faculty tutors are always more effective, because in the first year they are not. Student tutors in the first year seem to be just as effective as faculty tutors, but perhaps for different reasons. Both senior students and faculty tutors may be able to meet the needs of first-year medical students, to demonstrate cognitive congruence. The situation seems different in the second year. The strengths and advantages of faculty tutors may slightly surpass those of senior student tutors in more clinically oriented tests. Our finding that second-year students benefit from faculty tutors on more clinically relevant tests is new, and thus requires more research to test its validity and to better understand the mechanisms that contribute to this phenomenon.

Comparing learner achievement between first- and second-year students acknowledges that the needs of learners change as they progress and develop, and that the same form of curriculum delivery or approach to learning, PBL or otherwise, may not be optimum at all times or at all stages of medical school. This adaptive approach is consistent with Das et al. (2002), who observed that successful tutors gave more help and support in early PBL tutorial experiences, but withdrew their support in later experiences. This finding supports the view that senior student tutors who provide more help and support for their younger peers may be providing an important service, especially as students begin their medical education journeys. Our study acknowledges that students grow as they learn, and that a different approach to learning might vary from one stage of the journey to another (Albanese, 2010; Das et al., 2002; Piaget, 1971; Vygotsky, 1978).

There are several limitations to our study, most of which result from conducting a natural experiment within a functioning medical school program. First, as explained earlier, tutor and student assignments to tutorial groups were not randomized but based on educational considerations. Second, it is important to note that senior medical students were paired with faculty supervisors who participated to varying degrees as part of the PBL group. Third, the faculty tutor group was somewhat heterogeneous, especially in the first year where $25 \%$ of the groups were tutored by a faculty member with a $\mathrm{PhD}$ and not an MD. Also, the MD tutor pool consisted of physicians from a variety of disciplines and across the full spectrum of activity in clinical practice.

We were expecting a greater difference between the MEQ and MCQ examinations as an indicator of clinical relevance. Perhaps we would have seen different results if the examinations had a wider spread, or if all the most clinically relevant questions from both exams were compared to the least clinically relevant questions. This ought to be considered in future studies.

Finally, since student tutors are volunteers, it suggests that they have a clear interest in being teachers. We must be cautious in generalizing these results as being applicable to all senior students who may be compelled into service as tutors. In addition to being volunteers, student tutors receive only a short orientation for tutoring PBL, and so must rely on their previous experiences as PBL group members. Like faculty members, senior medical students enter this role with varying degrees of teaching experiences, and varying clinical experiences relevant to the objectives of the PBL courses to which they are assigned. They may perform differently, likely better, as they gain experience as tutors.

\section{Conclusion}

Due to the prevalence of senior student PBL tutors both at JABSOM and around the globe, this study sought to determine whether there might be an advantage to having a faculty tutor compared to having a senior student tutor in the first- and second-years of medical school on the scores of two different types of examinations. Though we found no differences for first-year students, there was a small difference in the second year on a more clinically oriented examination. Further research is needed to confirm and explore these findings and to illuminate the mechanisms, especially the role of the various types of tutors-students and faculty members-by which this effect is realized.

\section{References}

Albanese, M. (2010). Problem-based learning. In T. Swanwick (Ed.), Understanding medical education: Evidence, theory and practice (pp. 37-52). London, UK: WileyBlackwell. 
Albanese, M., \& Mitchell, S. (1993). Problem-based learning: A review of literature on its outcomes and implementation issues. Academic Medicine, 68(1), 52-81.

Barrows, H. S. (1986). A taxonomy of problem-based learning methods, Medical Education, 20(6), 481-486. http:// dx.doi.org/10.1111/j.1365-2923.1986.tb01386.x

Barrows, H., \& Wee Keng Neo, L. (2007). Principles and practice of a PBL. Singapore: Pearson Prentice Hall.

Bereiter, C., \& Scardamalia, M. (2000). Commentary on part $\mathrm{I}$ : Process and product in problem-based learning (PBL) research. In D. H. Evensen \& C. E. Hwelo (Eds.), Problembased learning: $A$ research perspective on learning interactions (pp. 185-195). Mahwah, NJ: Lawrence Erlbaum Associates, Inc.

Bulte, C., Betts, A., Garner, K., \& Durning, S. (2007). Student teaching: Views of student near-peer teachers and learners. Medical Teacher, 29(6), 583-590. http://dx.doi .org/10.1080/01421590701583824

Das, M., Mpofu, D. J. S., Hasan, M. Y., \& Stewart, T. S. (2002). Student perceptions of tutor skills in problem-based learning tutorials. Medical Education, 36(3), 272-278. http:// dx.doi.org/10.1046/j.1365-2923.2002.01148.x

Davis, W. K., Nairn, R., Paine, M. E., Anderson, R. M., \& Oh, M. S. (1992). Effects of expert and non-expert facilitators on the small-group process and on student performance. Academic Medicine, 67(7),470-474. http://dx.doi .org/10.1097/00001888-199207000-00013

de Volder, M. L., de Grave, W. S., \& Gijselaers, W. H. (1985). Peer teaching: Academic achievement of teacher-led versus student-led discussion groups. Higher Education, 14(6), 643-650. http://dx.doi.org/10.1007/BF00136502

Dolmans, D. H. J. M., Gijselaers, W. H., Moust, J. H. C., Degrave, W. S., Wolfhagen, I. H. A. P., \& Van der Vlueten, C. P. M. (2002). Trends in research on the tutor in problem-based learning: Conclusions and implications for educational practice and research. Medical Teacher, 24(2), 173-180. http://dx.doi.org/10.1080/01421590220125277

Eagle, C. J., Harasym, P. H., \& Mandin, H. (1992). Effects of tutors with case expertise on problem-based learning issues. Academic Medicine, 67(7), 465-469. http://dx.doi .org/10.1097/00001888-199207000-00012

Kassab, S., Abu-Hijleh, M. F., Al-Shboul, Q., \& Hamdy, H. (2005). Student-led tutorials in problem-based learning: Educational outcomes and students' perceptions. Medical Teacher, 27(6), 521-526. http://dx.doi .org/10.1080/01421590500156186

McKee, N., D'Eon, M., \& Trinder, K. (2013). Problembased learning for interprofessional education: Evidence from an interprofessional problem-based module on palliative care. Canadian Medical Education Journal, 4(1), e35-e48.
Moust, J. H. C., de Volder, M. L., \& Nuy, H. J. P. (1989). Peer teaching and higher level cognitive learning outcomes in problem-based learning. Higher Education, 18(6), $737-$ 742. http://dx.doi.org/10.1007/BF00155664

Moust, J. H. C., \& Schmidt, H. G. (1995). Facilitating smallgroup learning: a comparison of student and staff tutors' behavior. Instructional Science, 22(4), 287-301. http:// dx.doi.org/10.1007/BF00891782

Piaget, J. (1971). Psychology and epistemology. Harmondsworth, Middlesex: Penguin Books.

Ross, H. S., \& Cameron, M. T. T. (2007). Peer assisted learning: A planning and implementation framework: AMEE Guide no. 30. Medical Teacher, 29(6), 527-545. http:// dx.doi.org/10.1080/01421590701665886

Schmidt, H. G., \& Moust, J. H. (2000). Factors affecting small group tutorial learning: A review of the research. In D. H. Evensen \& C. E. Hwelo (Eds.), Problem-based learning: A research perspective on learning interactions (pp. 19-51). Mahwah, NJ: Lawrence Erlbaum Associates, Inc.

Sobrol, D. T. (1994). Peer tutoring and student outcomes in a problem-based course. Medical Education, 28(4), 284-289. http://dx.doi.org/10.1111/j.1365-2923.1994.tb02713.x

Ten Cate, O., \& Durning, S. (2007a). Dimensions and psychology of peer teaching in medical education. Medical Teacher, 29(6), 546-552. http://dx.doi .org/10.1080/01421590701583816

Ten Cate, O., \& Durning, S. (2007b). Peer teaching in medical education: Twelve reasons to move from theory to practice. Medical Teacher, 29(6), 591-599. http://dx.doi .org/10.1080/01421590701606799

Ten Cate, O., van de Vorst, I., \& van den Broek, S. (2012). Academic achievement of students tutored by near-peers. International Journal of Medical Education, 3, 6-13. http:// dx.doi.org/10.5116/ijme.4f0c.9ed2

Topping, K. J. (1996). The effectiveness of peer tutoring in further and higher education: a typology and review of the literature. Higher Education, 32(3), 321-345. http:// dx.doi.org/10.1007/BF00138870

Vygotsky, L. S. (1978). Mind in society: The development of higher psychological processes. Cambridge, MA: Harvard University Press.

Walsh, A. (2005). The tutor in problem-based learning: A novice's guide. Hamilton, Ontario: McMaster University.

Zeitz, H. J., \& Paul, H. (1993). Facilitator expertise and problem-based learning in PBL and traditional curricula. Academic Medicine, 68(3), 203-204.

Damon Sakai is currently an associate professor of medicine and the director of the Office of Medical Education at the University of Hawaii at Manoa John A. Burns School of Medicine (JABSOM). He is an active teacher and has served 
as a course director for many classes utilizing problembased learning. Sakai supervises PBL tutor training at JABSOM and has delivered many international workshops on using PBL in medical education. He has received numerous teaching awards including the Board of Regents Medal for Excellence in Teaching. His interests include curriculum development, PBL, faculty development, medical school accreditation, and educational leadership. Correspondence concerning this article should be addressed to Damon Sakai, John A. Burns School of Medicine, University of Hawaii, MEB-OME, 651 Ilalo Street, Honolulu, Hawaii 96813; damon@hawaii.edu.

Marcel D'Eon is currently a professor in the department of community health and epidemiology at the College of Medicine of the University of Saskatchewan. He has been active leader of faculty development and played a major role in the school's curriculum development and renewal. He conducts research and publishes in many diverse fields related to medical education. He is a former president of the Canadian Association for Medical Education and interim editor of the Canadian Medical Education Journal. His interests include faculty development, curriculum content management, interprofessional education, student wellness and professional identity formation, and evidence-based medicine for medical students.
Krista Trinder is currently a program evaluation specialist at the College of Medicine of the University of Saskatchewan. She is involved in program evaluation and medical education research in various areas, including aggregate self-assessment, medical school accreditation, and course and instructor evaluation. Trinder is a credentialed evaluator with the Canadian Evaluation Society and chairs the Program Evaluation Subcommittee at the College of Medicine of the University of Saskatchewan.

Richard Kasuya is currently the associate dean for Medical Education and professor of medicine at the University of Hawaii at Manoa John A. Burns School of Medicine. He is an active teacher across all four years of the medical student curriculum, and has over 20 years of experience as a PBL tutor and PBL course director. In 1996 he became the first clinician-educator from JABSOM to receive the University of Hawaii Board of Regents Medal for Excellence in Teaching, and is a two-time recipient of the John M. Hardman Award for Mentoring in Teaching. His interests include faculty development in problem-based learning, clinical teaching, evidence-based medicine, curriculum development, and educational leadership. He is board-certified in internal medicine, and a fellow of the American College of Physicians. 